\title{
CRIMINAL PROCEDURE TRUTH IN THE SYSTEM OF EVALUATIVE CATEGORIES
}

\author{
Vladimir M. Shynkaruk \\ Volgograd State University, Volgograd, Russian Federation
}

Introduction: determining the content of evaluative vocabulary in criminal procedure law and the proposed classification of evaluative expressions determine the formulation of the problem of ambiguity in referring certain terms to the evaluative category. It is noted that evaluative concepts, ambiguous in nature, and concepts, incorrectly and inappropriately used in legal framing are often mistakenly mixed. In this regard, the purpose of the research is to distinguish proper evaluative concepts from concepts of fuzzy and indefinite, as well as to differentiate the first ones depending on the degree of abstraction, thus showing the system of evaluative categories. The methodological framework for the study is the general scientific (dialectical, systemic, structural and functional, logical, etc.) and the specific scientific (formal legal, comparative law, historical and legal, etc.) research methods. Results: the author's point of view on the criminal procedure truth as an evaluative category is shown. Before that, in numerous works devoted to the establishment of truth in criminal proceedings it was primarily about the nature of the truth whether it is objective or subjective, formal, and whether to consider it as a purpose of criminal proceedings. Conclusions: the criminal procedure truth should be considered as an evaluative category, regardless of whether it is fixed at the legislative level or not. Thus, it is concluded that there is a system of evaluative categories in the criminal process, including concepts which are different in abstraction degrees, regardless of their legal consolidation.

Key words: evaluative categories, evaluative vocabulary, interpretation, subjective factor, differentiation, truth, procedure truth.

Citation. Shynkaruk V.M. Criminal Procedure Truth in the System of Evaluative Categories. Legal Concept, 2019, vol. 18, no. 2, pp. 63-68. (in Russian). DOI: https://doi.org/10.15688/lc.jvolsu.2019.2.9

УДК 343.13

ББК 67.410 .2
Дата поступления статьи: 02.03.2019 Дата принятия статьи: 15.03.2019

\section{УГОЛОВНО-ПРОЦЕССУАЛЬНАЯ ИСТИНА В СИСТЕМЕ ОЦЕНОЧНЫХ КАТЕГОРИЙ}

\author{
Владимир Маркович Шинкарук \\ Волгоградский государственный университет, г. Волгоград, Российская Федерация
}

\begin{abstract}
Введение: определение содержания оценочной лексики в уголовно-процессуальном праве и предложенная классификация оценочных выражений обусловливают постановку проблемы неоднозначности в отнесении отдельных терминов к категории оценочных. Отмечается, что зачастую ошибочно смешиваются оценочные понятия, неоднозначные по своей сущности, и понятия, неверно и не к месту используемые при конструировании правовых норм. В этой связи была поставлена цель разграничения собственно оценочных понятий от понятий нечетких и неопределенных, а также дифференцировать первые в зависимости от степени абстрактности, таким образом показав систему оценочных категорий. Методологическую основу работы составили общенаучные (диалектический, системный, структурно-функциональный, логический и др.) и частнонаучные (формально-юридический, сравнительно-правовой, историко-правовой и др.) методы исследования. Результаты: изложена авторская позиция по поводу уголовно-процессуальной истины как оценочной категории. До этого в многочисленных работах, посвященных установлению истины в уголовном процессе, речь шла, прежде всего, о характере истины - объективная она или субъективная, формальная, и стоит ли рассматривать ее в качестве цели уголовного судопроизводства. Выводы: уголовно-процессуаль-
\end{abstract}


ную истину следует рассматривать как оценочную категорию, независимо от того, закреплена она на законодательном уровне или нет. Таким образом делается вывод о существовании в уголовном процессе системы оценочных категорий, включающей различные по степени абстракции понятия, независимо от их легального закрепления.

Ключевые слова: оценочные категории, оценочная лексика, интерпретация, толкование, субъективный фактор, дифференциация, истина, процессуальная истина.

Цитирование. Шинкарук В. М. Уголовно-процессуальная истина в системе оценочных категорий // Legal Concept = Правовая парадигма. - 2019. - Т. 18, № 2. - C. 63-68. - DOI: https://doi.org/10. 15688/lc.jvolsu.2019.2.9

\section{Введение}

Проблема неоднозначности в отнесении отдельных терминов к категории оценочных и их толковании по-прежнему актуальна и требует глубокого изучения и анализа. Зачастую ошибочно смешиваются оценочные понятия, неоднозначные по своей сущности, и понятия, неверно и неуместно используемые при конструировании правовых норм. Поэтому следует определиться с природой оценочных понятий и непосредственно с тем, что следует к ним относить. Важно разграничивать вопросы использования оценочной лексики, правовой неопределенности отдельных норм и различных видов толкования норм. Тогда будет понятно, какие понятия, используемые в уголовном судопроизводстве, относятся к собственно оценочным, а каким ошибочно придается оценочный характер.

\section{Теоретическое и прикладное значение оценочных категорий \\ в уголовном праве и процессе}

Оценочные понятия и категории прочно вошли в отечественное законодательство, поскольку от их грамотного толкования и использования зависит эффективность обеспечения прав и свобод граждан в уголовном судопроизводстве [21, с. 129].

В юридической литературе не сформировалось единого мнения о правовой природе и сущности оценочных понятий [1]. Но, как бы не хотелось обойтись и законодателю и правоприменителю без использования оценочной лексики, этого никогда не произойдет [1]. Существование подобной лексики детерминировано такими факторами, как постоянно изменяющиеся общественные отношения, нестабильность социальной обстановки, много- аспектность человеческой деятельности [7, с. 13]. Названные предпосылки обусловливают целесообразность говорить об оценочных понятиях и категориях не только применительно к официально закрепленным терминам, но и используемым на практике. В частности, это относится к такой категории, как истина в уголовном процессе. В действующем УПК РФ не предусмотрена она в качестве цели судопроизводства, но сама категория имеет место быть, и вокруг ее содержания не стихают дискуссии и споры.

Многие оценочные категории, которые невозможно оценить с точки зрения соответствия правовым нормам либо каким-либо иным образом «ощутить», сопоставить, давно употребляются в уголовно-процессуальном законодательстве, и их наличие в системе принципов не вызывает бурных споров, например, «совесть» и «внутреннее убеждение». При всей строгости и конкретности уголовно-процессуальных норм такие морально-этические категории нужны непременно [2].

С другой стороны, представляется спорным отнесение некоторых положений к оценочным таких понятий, например: «правовая и фактическая сложность уголовного дела»; «поведение участников уголовного судопроизводства»; «достаточность и эффективность действий суда, прокурора, руководителя следственного органа, следователя, органа дознания, начальника органа дознания, начальника подразделения дознания, дознавателя, производимых в целях своевременного осуществления уголовного преследования или рассмотрения уголовного дела» [2]. В данном случае смешиваются собственно оценочные понятия и неопределенность терминов, либо нечеткость их формулирования и неуместное использование. Произвольная интерпретация ряда понятий может осуществляться как от наличия в 
их содержании оценочного характера, так и от неграмотности и неумения четко формулировать нужные положения.

Таким образом, вопросы, связанные с применением оценочных понятий, можно признать не единственными в части их терминологической неопределенности. Опасность заключается в неточности использования понятий, первоначально не несущих в себе соответствующей смысловой нагрузки [17].

\section{Классификация оценочного терминологического аппарата}

\section{и истина как оценочная категория}

Назрела необходимость дифференциации оценочного терминологического аппарата [5, c. $15 ; 15$, с. 403]. Целесообразно дифференцировать всю оценочную лексику, используемую в уголовном процессе, в зависимости от степени абстрактности и обобщенности тех или иных понятий $[4$, с. $21 ; 6$, с. $120 ; 8$, с. $145 ; 9$, с. $18 ; 16 ; 18$, с. 97].

Отнесение истины к оценочным категориям будет способствовать рассмотрению ее под иным углом, и, возможно, более глубокому и детальному изучению. До настоящего времени вопрос об отнесении истины к оценочным понятиям не ставился, хотя ее содержание обсуждалось и обсуждается очень бурно. Дискуссии возникают как о ее характере, субъективном или объективном, так и вообще о целесообразности и возможности достижения таковой в уголовном судопроизводстве [13].

Очевидно, что категория истины достаточно сложная, и в этом вопросе нет единства мнений. Но вне зависимости от того, будет истина называться объективной или субъективной, без человеческого фактора она не может быть достигнута. Отсюда и вариативность интерпретации истины в уголовном процессе. Отсюда и предпосылки отнесения ее к разряду оценочной лексики.

Вопрос о характере истины, устанавливаемой в уголовном процессе, издавна интересовал выдающиеся умы [12; 20, с. 189 190]. Истина, являясь продуктом умственной деятельности, не может быть объективной, как не может быть объективным любое отражение предмета взамен самого предмета $[3$, с. 102].

\section{Уголовно-процессуальная истина как объект исследования}

Удачным и заслуживающим одобрения представляется предложение Н.В. Пальчиковой выделить термин «процессуальная истина» в качестве термина, определяющего характер истины в уголовно-процессуальном познании [10]. Это объясняет также, что именно процессуальная истина может быть отнесена к оценочным категориям. Кроме того, в пользу такого подхода говорит и установленный законом разумный срок расследования и рассмотрения уголовного дела [14]. Нравственный смысл познавательной деятельности по установлению истины также свидетельствует о возможности отнесения ее к оценочным категориям [11].

В определенной мере доказательством того, что формально-юридическая (правовая) истина относится не к объективной, а к субъективной области, служит ее характеристика, данная, например, Д.П. Туленковым: «Содержание правовой истины в рамках уголовного судопроизводства в большей степени сводится к внутренней согласованности и логической непротиворечивости системы утверждений при наличии связей между ними (принцип когеренции), чем к соответствию полученного судом знания объективному положению дел предметного мира, в частности, исследуемым событиям, связанным с предъявленным лицу обвинением» [19, с. 10]. Чем не аргумент в пользу того, что процессуальная истина является оценочной категорией.

\section{Выводы}

Сложности законодательной техники и правоприменительной практики могут быть обусловлены не только введением в законодательство тех или иных оценочных понятий, но и их формальным исключением, при сохранении фактического присутствия [17]. В данном контексте речь идет об истине, которая предусматривалась в УПК РСФСР, а в соответствии с УПК РФ нет. Вместе с тем истина не перестает быть предметом острых споров и дискуссий, подчеркивающих ее значимость для уголовного процесса. Среди множества оценочных определений, которым традиционно уделяется пристальное внимание и 
об интерпретации которых ведутся дискуссии, такая категория, как истина, не упоминалась. Возможно, это обусловлено сложностью и неоднозначностью данной категории, ее философской наполненностью. Но ведь именно эти характеристики и предопределяют отнесение тех или иных понятий к оценочным. Возможно, рассмотрение истины с точки зрения ее оценочного характера создаст дополнительные трудности при раскрытии ее сущности. И, наконец, нельзя забывать, что, говоря об истине в уголовном процессе как оценочной категории, прежде всего имеется в виду истина процессуальная.

\section{СПИСОК ЛИТЕРАТУРЫ}

1. Гармышев, Я. В. Особенности установления оценочных понятий при квалификации отдельных видов преступлений / Я. В. Гармышев // Российский следователь. - 2015. - № 19. - С. 35-39.

2. Головинская, И. В. О принципах и сроках в уголовном судопроизводстве / И. В. Головинская, И. И. Савельев // Современное право. - 2019. - № 1. C. 111-117.

3. Гриненко, А. В. Система принципов уголовного процесса и ее реализация на досудебных стадиях : дис. ... д-ра юрид. наук / Гриненко Александр Викторович. - Воронеж, 2001. - 471 с.

4. Кобзева, Е. В. Оценочные понятия в уголовном законе : автореф. дис. ... канд. юрид. наук / Кобзева Елена Васильевна. - Саратов, 2002. - 34 с.

5. Коробец, Б. Н. Оценочные понятия в российском уголовном праве (социальная обусловленность и юридическая сущность) : автореф. дис. ... канд. юрид. наук / Коробец Борис Николаевич. M., 2007. $-21 \mathrm{c}$.

6. Кудрявцев, В. Н. Теоретические основы квалификации преступлений / В. Н. Кудрявцев. - М. : Госюриздат, 1963.- $196 \mathrm{c}$.

7. Левина, Д. Н. Теоретические проблемы толкования и применения оценочных понятийм : автореф. дис. ... канд. юрид. наук / Левина Дарья Николаевна. - Н. Новгород, 2007. - 36 с.

8. Марфицин, П. Г. Усмотрение следователя: уголовно-процессуальный аспект : дис. ... д-ра юрид. наук / Марфицин Павел Григорьевич. - Омск, 2003.$418 \mathrm{c}$.

9. Опалев, Р. О. Оценочные понятия в арбитражном и гражданском процессуальном праве / Р. О. Опалев. - М. : Волтерс Клувер, 2008. $248 \mathrm{c}$.

10. Пальчикова, Н. В. К вопросу о характере истины в уголовно-процессуальном познании
/ Н. В. Пальчикова // Общество и право. - 2009. № 5. - C. 243-247.

11. Печников, Г. А. Примиримы ли в УПК РФ формально-юридическая и объективная (материальная) истина? / Г. А. Печников, Н. А. Соловьева, В. М. Шинкарук // Logos et Praxis. - 2018. - № 4. C. 61-67.

12. Печников, Г. А. Устав уголовного судопроизводства 1864 года - коренной переход от формальной к объективной (материальной) истине и актуальные проблемы истины в современном УПК РФ / Г. А. Печников, Н. А. Соловьева, В. М. Шинкарук // Вестник Волгоградского государственного университета. Серия 5, Юриспруденция. - 2015. № 1 (26). - C. $42-48$.

13. Соловьева, Н. А. Значение дифференциации оценочного терминологического аппарата для модернизации уголовно-процессуальной деятельности / Н. А. Соловьева // Вестник Волгоградского государственного университета. Серия 5, Юриспруденция. -2013 . - № 2 (19). - С. 143-150.

14. Соловьева, Н. А. Интерпретация истины в уголовном процессе: компаративный анализ / Н. А. Соловьева, В. М. Шинкарук // Вестник Волгоградского государственного университета, Серия 7, Философия. - 2016. - № 3 (3). - С. 56-62.

15. Соловьева, Н. А. Оценочные выражения в уголовном процессе / Н. А. Соловьева // Актуальные проблемы защиты социально-экономических прав человека в России, СНГ и странах Европейского Союза : материалы Междунар. науч. конф., Волгоград, 6-7 июня 2014 года. Т. 1. - Волгоград : Изд-во ВолгГМУ, 2014. - 504 с.

16. Соловьева, Н. А. Совершенствование интерпретационной практики применения оценочных выражений уголовно-процессуального законодательства / Н. А. Соловьева // Правоприменительная политика в современной России: проблемы формирования и осуществления : материалы Междунар. круглого стола, г. Волгоград, 16 мая 2013 г. / под ред. И. В. Ростовщикова. - Волгоград : Изд-во ВолГУ, 2013. - С. 192-201.

17. Соловьева, Н. А. Терминологическая проблема определения восстановительного правосудия / Н. А. Соловьева, В. М. Шинкарук // Вестник Волгоградского государственного университета. Серия 5, Юриспруденция. - 2013. - № 3 (20). C. 104-109.

18. Ткешелиадзе, Г. Т. Судебная практика и уголовный закон / Г. Т. Ткешелиадзе. - Тбилиси : Мецниереба, 1975. - 175 с.

19. Туленков, Д. П. Познавательная деятельность при производстве по уголовным делам с участием присяжных заседателей : автореф. дис. ... канд. юрид. наук / Туленков Дмитрий Петрович. - Волгоград, 2017. $-252 \mathrm{c}$. 
20. Фойницкий, И. Я. Курс уголовного судопроизводства. В 2 т. Т. 2 / И. Я. Фойницкий. - СПб. : Альфа, 1996. - 607 с.

21. Черепанова, Е. В. Оценочные понятия в УК РФ и их влияние на эффективность применения уголовного законодательства / Е. В. Черепанова // Журнал российского права. - 2009. - № 2. C. $128-134$.

\section{REFERENCES}

1. Garmyshev Ja.V. Features of Establishment of Estimated Concepts at Qualification of Separate Types of Crime. Rossiyskiy sledovatel, 2015, no. 19, pp. 3539. (in Russian).

2. Golovinskaja I.V., Savel'ev I.I. About the Principles and Terms in Criminal Trial. Sovremennoe pravo, 2019, no. 1, pp. 111-117. (in Russian).

3. Grinenko A.V. The System of the Principles of Criminal Procedure and its Realization at PreJudicial Stages. Voronezh, 2001. 471 p. (in Russian).

4. Kobzeva E.V. Estimated Concepts of the Criminal Law. Saratov, 2002. 34 p. (in Russian).

5. Korobec B.N. Estimated Concepts of the Russian Penal Law (Social Conditionality and Legal Essence). Moscow, 2007. 21 p. (in Russian).

6. Kudrjavcev V.N. Theoretical Bases of Qualification of Crimes. Moscow, Gosyurizdat Publ., 1963. 196 p. (in Russian).

7. Levina D.N. Theoretical Problems of Interpretation and Application of Estimated Concepts. N. Novgorod, 2007. 36 p. (in Russian).

8. Marficin P.G. Investigator's Discretion: Criminal Procedure Aspect. Omsk, 2003. 418 p. (in Russian).

9. Opalev R.O. Estimated Concepts of an Arbitration and Civil Procedural Law. Moscow, Volters Kluver Publ., 2008. 248 p. (in Russian).

10. Pal'chikova N.V. To a Question of the Nature of the Truth in Criminal Procedure Knowledge. Obshhestvo i pravo, 2009, no. 5, pp. 243-247. (in Russian).

11. Pechnikov G.A., Solov'eva N.A., Shinkaruk V.M. Whether are Reconcilable in the CCP of the RF the Legallistic and Objective (Material) Truth? Logos et Praxis, 2018, no. 4, pp. 61-67. (in Russian).
12. Pechnikov G.A., Solov'eva N.A., Shinkaruk V.M. The Charter of Criminal Trial of $1864-$ Radical Transition from Formal to the Objective (Material) Truth and Current Problems of the Truth in the Modern CCP of the RF. Science Journal of Volgograd State University. Jurisprudence, 2015, no. 1 (26), pp. 42-48. (in Russian).

13. Solov'eva N.A. Value of Differentiation of an Estimated Terms Framework for Modernization of Criminal Procedure Activity. Science Journal of Volgograd State University. Jurisprudence, 2013, no. 2 (19), pp. 143-150. (in Russian).

14. Solov'eva N.A., Shinkaruk V.M. Interpretation of the Truth in Criminal Procedure: Komparativny Analysis. Science Journal of Volgograd State University. Philosophy, 2016, no. 3 (3), pp. 56-62. (in Russian).

15. Solov'eva N.A. Estimated Expressions in Criminal Procedure. Current Problems of Protection of Social and Economic Human Rights in Russia, the CIS and the Countries of the European Union: Materials of the International Scientific Conference. Volgograd, VolgGMU Publ., 2014, vol. 1. 504 p. (in Russian).

16. Solov'eva N.A. Improvement of Interpretative Practice of Application of Estimated Expressions of the Criminal Procedure Legislation. Enforcement Policy in Modern Russia: Problems of Formation and Implementation. Volgograd, VolGU Publ., 2013, pp. 192201. (in Russian).

17. Solov'eva N.A., Shinkaruk V.M. Terminological Problem of Definition of Recovery Justice. Science Journal of Volgograd State University. Jurisprudence, 2013, no. 3 (20), pp. 104109. (in Russian).

18. Tkesheliadze G.T. Court Practice and Criminal Law. Tbilisi, Metsniyereba Publ., 1975. 175 p. (in Russian).

19. Tulenkov D.P. Cognitive Activity by Criminal Cases Production with Participation of Jury Members. Volgograd, 2017. 252 p. (in Russian).

20. Fojnickij I.Ja. Course of Criminal Trial. Saint Petersburg, Alfa Publ., 1996, vol. 2. 607 p. (in Russian).

21. Cherepanova E.V. Estimated Concepts of the $\mathrm{CC}$ of the RF and their Influence on Efficiency of Application of the Criminal Legislation. Zhurnal rossiyskogo prava, 2009, no. 2, pp. 128-134. (in Russian). 


\section{Information about the Author}

Vladimir M. Shynkaruk, Candidate of Sciences (Jurisprudence), Associate Professor, Department of Criminal Procedure and Criminology, Volgograd State University, Prosp. Universitetsky, 100, 400062 Volgograd, Russian Federation, shinkaruk@volsu.ru, shinkarukvm@gmail.com, https://orcid.org/00000002-1047-4475

\section{Информация об авторе}

Владимир Маркович Шинкарук, кандидат юридических наук, доцент кафедры уголовного процесса и криминалистики, Волгоградский государственный университет, просп. Университетский, 100, 400062 г. Волгоград, Российская Федерация, shinkaruk@volsu.ru, shinkarukvm@gmail.com, https://orcid.org/0000-0002-1047-4475 